\title{
A Preliminary Exploration of Management Problems in the Wisdom Transformation of Chifeng College Library
}

\author{
Man Jiang \\ Logistics Services Management Centre, National Library of China, Beijing ,100081, China \\ *Corresponding author's e-mail: jiangman1983@126.com
}

\begin{abstract}
The main purpose of this paper is to explore in depth the problems in management in the process of the transformation of Chifeng College Library to the Wisdom Library. It is proposed to reform and upgrade in six aspects: optimizing the organizational structure, facing readers, increasing self-service equipment, adjusting the spatial environment, innovating interactive means and focusing on talent training, so that the Chifeng College Library can better adapt to the requirements of the transformation and development of the smart library.
\end{abstract}

Keywords: Wisdom library, intelligent library, transformation of library to the Wisdom Library

\section{Introduction}

With the advent of the $5 \mathrm{G}$ era, as an information service department, the library facing the rapid development of the information age, its traditional management mode is no longer suitable for the development of the times. With the concept of intelligent earth and smart city, the concept of the smart library came into being. In recent years, the research of scholars in the domestic library about the related subjects of the wisdom map in library has been increasing year by year. The intelligent library is a new form of existence. Its appearance has upended people's long-standing traditional stereotype of the library. For the continuous development of science and technology in the society, the emergence of the intelligent library is in line with the development of the times, and it is to meet the needs of a form of reading of readers and users. Its development will closely follow the times and the development of science and technology, and walk in the reader and users of the reading needs of the forefront. Therefore, the wisdom library is a kind of long-term survival of the development form [1-3].

The Chifeng College Library was merged by the former Chifeng National Normal College, Chifeng College of Education, Chifeng University of Inner Mongolia Radio and Television, Inner Mongolia Early Childhood Normal School, Chifeng Health School, Chifeng Art School, and was officially established in July 2003. Now the college library has begun to take shape, which can meet the basic needs of teaching and scientific research in undergraduate colleges. The library has now relocated a new library with the library area of 29,000 square meters, the collection of paper books 1.208 million copies, 616,000 copies of ebooks, and 14686 kinds of electronic periodicals; According to the existing conditions of Chifeng College Library and combined with the characteristics of the smart library, the following targeted and operable improved strategies and methods are put forward.

\section{Optimizing the organizational structure}

At present, the organizational structure of Chifeng College Library is mainly around the basic business as the core, and the core of the operation of the intelligent library organization is oriented to the needs of readers. In this organizational structure, the establishment of institutions and the functions of departments can be flexibly adjusted according to the needs of readers. The object of library service is mainly the teacher and student group. The part of the group for the information resources demand, for the content, mode and means of information resources have higher requirements. Readers use the library not only to use a book or a kind of literature, but also to find knowledge, reference value, accurate source, data authority of a collection of information. To meet the needs of readers, we need to integrate the strength of various departments of the library. And at present, the organization of libraries is too detailed, that it can not meet the needs of readers for "one-stop" information access services. This can be adjusted by merging departments with similar structural functions, streamlined service processes, and simplifying the requirements for readers to use library procedures. In the context of departmental consolidation, it is not possible to break the boundaries between departments, to fragment the functions of each department, and to integrate departments with similar functions, in order to seek a longer-term development for the Chifeng College Library in the future.

\section{For readers}

At present, the main service model of Chifeng College Library is "business-centric", and for the current period of change, such a service model is undoubtedly a closed-door car. For the reader, the source of information is already in 
short supply, if the library cannot actively understand the needs of readers, then one day the library will be abandoned by readers. And that users and readers to participate in the design of new services is another attempt of user relationship management is breaking the library has been mainly library-based, user-assisted fixed mode. Therefore, the library service object is mainly teachers and students. When the library plan to provide readers with a new service, inviting readers to participate in the service design will greatly improve the satisfaction of the service. To increase the degree of bonding between the library and the user through interaction with the user, readers can not only learn to read in the library, but also participate in the construction of the library. It gives themselves the opportunity to exercise and display themselves, thus breaking the boundary between the library and the reader, so that the two are more intimate.

\section{Increase self-service equipment}

For the smart library, the library basic business can basically be done through intelligent self-service equipment. For the Chifeng College Library, during various examinations, the library's seating resources are particularly tight. In order to using the library's reading seats for a long time, many readers use personal items for the seat, so that other readers cannot equally access to the library's reading resources. Therefore, the introduction of intelligent seat selection system solves this problem completely. At the same time, white loan-help machine can help readers to borrow books easily, but also can return the book over-term fines. It not only improves the efficiency of loan repayment and the satisfaction of readers, but also relieves the pressure of library staff' work. In addition, you can also set up self-service printers, selfservice readers and white coffee machines. The introduction of intelligent self-service equipment has greatly improved the satisfaction of readers to the library to enjoy the service.

\section{Adjusting the space environment}

In the process of transformation to the smart library, librarians began to consider more about how to plan and design to transform the library space, for the readers' needs of the library in the new period have also changed a lot. Not only the needs of basic reading but also the needs of readers exchange discussion, innovation and development, leisure and entertainment need to be met. And every requirement needs to be customized and appropriately space. With the gradual upgrading of the indoor environment of the library, the number of readers who come to the library to learn and exchange is also gradually increasing. Especially in the university library, the seat resources are very tight in the examination season, result in the phenomenon of saving seats sometimes occurs. Therefore, the re-transformation of space will give way to the audience. Firstly, it is to build a closed-frame library. It integrates the library's older use of low-use book collection into the closed-frame library, and the original space for books placed into a reading area or multifunctional space expansion area. Secondly, the space of the functional area division of the intelligent library is set in the original reading and learning space, more attention to the readers to the library's diverse needs. Last of all, for the need to exchange seminars, a region as a reader's exchange discussion use is divided.

\section{Innovative means of interaction}

For the traditional library, the amount of push information is limited, and the audience range is narrow, and the dissemination effect is slow. In addition, the new media than traditional media has many advantages. First of all, the new media has a variety of forms of expression. It can be text image video audio, and be also animation Flash. Such as, this variety of forms of expression greatly increased the reader's experience, in the visual and sound, it can give the reader a refreshing feeling. Second, it is very fast-to-subscribe, because readers can subscribe to the information of interest to themselves according to their own preferences. For this form of the new media, it can push a large amount of personalized information, but also set the search function for the reader in the search area. Finding their own interest in information for reading, information for readers to become a one-to-one very targeted push, has changed that readers do not choose the function, but can only passively accept the transmission of information bureau in the past. For example, to express opinions, to participate in activities, to participate in production, etc. has promoted the spread and promotion of culture. The last advantage of the new media is that it has low-cost characteristics. For mobile phones and other mobile terminals generally popularized stage, users can access the mobile terminal at any time and place above the information. Compared with the traditional media communication mode, it reduces printing, logistics, delivery and other links. It not only improves the efficiency of distribution, but also reduces cost and saves resource waste. Library's new media services are diverse, such as mobile phone libraries, official library micro blogs, library We Chat public platforms, library mobile applications, digital tv libraries and so on.

\section{Focus on talent development}

In the development process of the university to the smart library, young librarians play a major role. To adopt active incentive policies and promotional system for young librarians, to mobilize the enthusiasm of young librarians, and to fully tap the inner potential of young librarians, for the future long-term development of university libraries play a very important role. For young librarians to establish a scientific system in line with their 
characteristics of the incentive mechanism, first of all, the principle of more work and more to achieve distribution according to work should be built. For example, in order to do more heavy work of young librarians for the library, their salary can be assessed according to their workload, then young librarians will be willing to engage in more heavy technical content and creative work. At the same time, for young librarians, the new concept of library transformation and development is easier to understand, for the library's reader service work can have more innovative ideas, and for the work can be quickly and actively implemented. Therefore, during the transformation of university libraries, it is very necessary to build a young professional librarian service team which plays a leading role in the development of the transformation process of university libraries. And the establishment of a system of professional incentive mechanism can effectively stimulate the enthusiasm of young team work, and stabilize the personnel structure. Moreover, it plays a very positive and important role to avoid brain drain.

\section{Conclusion}

As the core department of information service sharing, university library plays an important role in serving and educating people. With the rapid development of $5 \mathrm{G}$ technology, the transformation and development of university library to the smart library will better carry the mission which given to the library in this historical stage. Chifeng College Library needs to optimize the organizational structure, and face the reader, and increase self-service equipment, and adjust the space environment, and use innovative interactive means , and pay attention to talent training in six aspects of reform and promotion, in order to be more in line with the wisdom library change of the times development needs.

\section{ACKNOWLEDGMENT}

I would like to express my gratitude to all those who helped me during the writing of this thesis. My deepest gratitude goes first and foremost to Mrs. Yang, who has provided me with necessary materials and advice of great value on my thesis. It is his suggestions that draw my attention to a number of deficiencies and make many things clearer. Without his support, the completion of this thesis would not have been possible. I shall extend my thanks to my department leaders, for them instructive advice and useful suggestions on my thesis. Last, I am indebted to my beloved family for their continuous support and encouragement

\section{REFERENCES}

[1] Forsman D. (2012) Change as a Service-Challenges and effects of a new paradigm for library systems and content infrastructure. Library Management, 33(8): 498-510.

[2] Chen. L. S. (2010) Applying swarm intelligence to a library system. Library Collection Acquisitions \& Technical Services, 34(1): 1-10.

[3] Noh Y. (2013) A study on next-generation digital library using context-awarenessm Technology. Library Hi Tech, 31(2): 236-253

[4] Berendt B, Krause B, Kolbe Nusser S (2010) Intelligent scientific authoring tooIs: InteractiVes data mining for constructive uses of citation network. Information Processing \& Management, 46(1): 1-10. 